\title{
Exploring Student and Teacher Experiences in Hybrid Learning Environments: Does Presence Matter?
}

\author{
Annelies Raes ${ }^{1,2,3}$
}

Accepted: 3 November 2021 / Published online: 18 November 2021

(c) The Author(s), under exclusive licence to Springer Nature Switzerland AG 2021

\begin{abstract}
The global pandemic forced us to rethink education to fight Covid-19 and apply social distancing during lectures. Luckily, we could rely on earlier research into distance education in general, and more specifically, into synchronous hybrid learning. During synchronous hybrid learning both on-site and remote students are connected and taught synchronously in what we call at our university the 'hybrid classroom' or 'hybrid lecture hall'. In order to further substantiate this potential new normal, research is needed to investigate the influencing factors of engagement and learning in these new environments from a student and teacher perspective. In this study, two different hybrid learning designs and practices are explored and analysed through the lens of the activity-centred analysis and design (ACAD) framework. Next to this more qualitative approach, this study also presents quantitative results on the effect of the level of presence (on-site versus remote, with or without interaction) on conceptual and affective outcomes. In terms of the student perspective, this study did not find any significant differences between physical and remote presence regarding conceptual understanding, yet significant differences were found in regard of affective engagement in favour of the on-site students and remote students having the opportunity to interact. In line with the ACAD framework, our research found that successful learning and teaching activities are interrelated with set, epistemic, and social design decisions.
\end{abstract}

Keywords Hybrid learning environments · Engagement $\cdot$ Learning space $\cdot$ Teaching space - User experience

Annelies Raes

annelies.raes@kuleuven.be

1 Faculty of Psychology and Educational Sciences, KU Leuven Campus Kulak Kortrijk, Etienne Sabbelaan 51 - box 7800, 8500 Kortrijk, Belgium

2 Itec, Imec Research Group at KU Leuven, Kapeldreef 75, 3001 Leuven, Belgium

3 CIREL (Centre Interuniversitaire de Recherche en Education de Lille) (ULR 4354), Université de Lille, Villeneuve-d’Ascq, France 


\section{Background of the Study}

Over the course of the last 15 years, more attention has been devoted towards learning and teaching spaces, with many researchers claiming that flexible spaces better meet the needs of a diverse student population (Amoroso 2014; Joy et al. 2013; Wang et al. 2018). JISC, a not-for-profit company in the UK that was set up to provide computing support for education, suggested in their report (2006) that a learning space should be able to motivate learners and promote learning as an activity, support collaborative as well as formal practice, provide a personalized and inclusive environment, and be flexible in the face of changing needs.

In line with this, the European University Association (European University Association 2021) imagines future universities to be without walls, meaning that universities will be open and engaged in society whilst at the same time retaining their core values. They will provide an open, transformative space for common knowledge production through research, education, innovation and culture. It is stated that together with other societal stakeholders, they will shape the future of a knowledge-driven society (European University Association 2021: 5).

These transformative spaces are also conceptualized as postdigital learning spaces, aiming to open up institutional spaces to form universities beyond traditional dichotomies (O'Bryrne and Pytash 2015). This means that in postdigital learning and teaching, physical environments merge with digital environments. As stated by Feenberg (2019), within postdigital learning spaces, the digital will be integrated and inherent in the everyday actions, interactions and experiences of teaching and learning.

In line with this societal and educational transition, KU Leuven, one of Europe's oldest universities located in Belgium, started in 2016 with the research project TECOL (see: https://www.kuleuven-kulak.be/tecol) to investigate how technology could be integrated to support future-proof teaching and learning. As KU Leuven is a multi-campus university spread across nine different cities, the project aimed to investigate how the various educational programs across the different campuses could become more flexible. In addition, the project aimed to investigate how the university would be able to better support expertise exchange and connectivity irrespective of place, in order to create a more open and multidisciplinary approach in which students get acquainted with different perspectives.

Creating hybridity starts with technical solutions and set-ups, and within the research and development project Lecture + (see https://www.imec-int.com/en/ what-we-offer/research-portfolio/lecture), a technological solution has been cocreated and accordingly been called the hybrid classroom. The hybrid classroom connects both on-site students and individual remote students during synchronous teaching and learning (see Fig. 1). This classroom is operational since 2017 and aims to provide the pedagogical freedom to reach students and teachers from any place in the world, increasing societal access to education as well as improving the quality of education, as knowledge now transcends the boundaries of the classroom. 


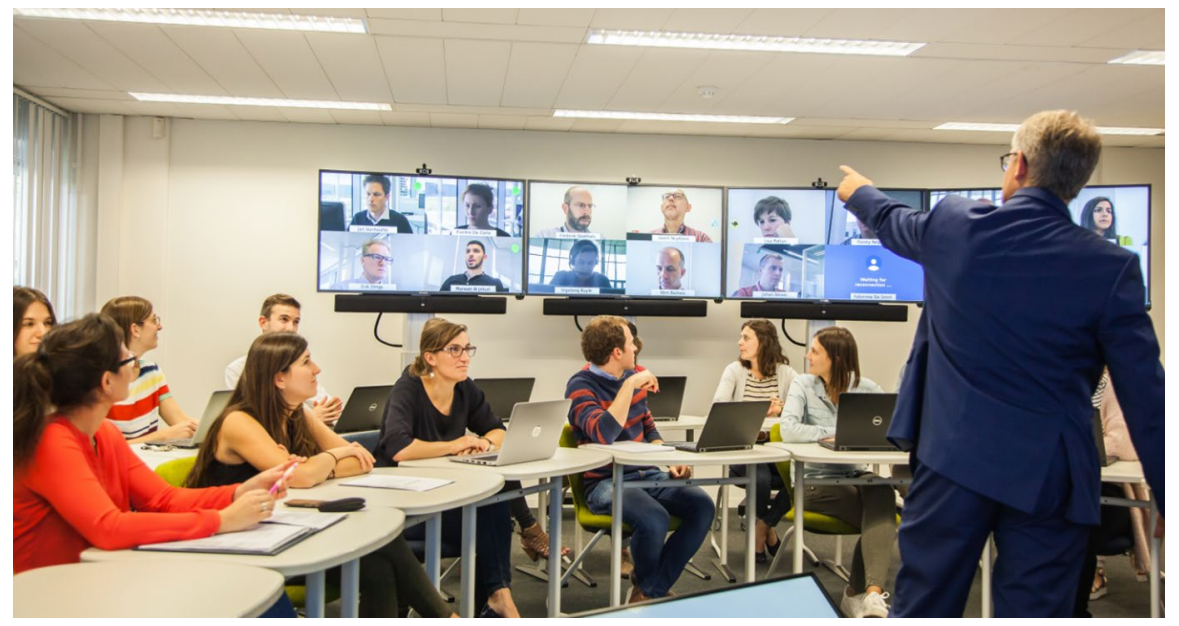

Fig. 1 Hybrid classroom implemented at KU Leuven, Campus Kulak Kortrijk @imec

\section{Creating Conceptual Clarity}

Although our university decided to conceptualize the concept of merging on-site and remote students at the same time as synchronous hybrid teaching and learning, many more concepts can be found in the literature that tries to capture the phenomenon of merging modes. Irvine (2020) emphasized the importance of focusing on the meaning of concepts in order to create a shared understanding for the future of our academic discourse. She provided an overview of the main terms, including hyflex, multi-access, (synchronous) blended and (synchronous) hybrid. The HyFlex (hybrid-flexible) model was developed by Beatty $(2007,2019)$ and is described as a combination of hybrid, i.e. combining both online and face-to-face modalities, and flexible, as students may choose whether or not to attend face-to-face sessions. With support from the Canada Foundation for Innovation, Irvine introduced the multiaccess learning model at the 2009 AACE EdMedia Conference and then expanded on the idea in a 2013 article (Irvine et al. 2013; Irvine 2020). The model identifies four levels of access: (1) face-to-face, (2) synchronous online, (3) asynchronous online and (4) open access. Hybrid and blended both refer to combining modes (Lakhal et al. 2017), but the term synchronously has later been added (see e.g. Shi et al. 2021; Zydney et al. 2020) as without this specification blended or hybrid are also used to describe learning scenarios operationalizing online and offline as dichotomies in which learning takes place either online or offline. Ladd (2020) (Dean of the San Francisco campus) for example mentioned in his article that he is reserving the term 'hybrid' for educational experiences where the students in a class group are either all online or all face-to-face in a classroom together. To describe a classroom which has both people online and in-person at the same time, Ladd (2020) put forth the term 'concurrent classroom'. Other less common terms are synchromodal (Bell et al. 2014) and dual-mode teaching, meaning that both online and classroombased instruction is provided in a course at the same time. The term dual-mode is 
used within CETL (Centre for the Enhancement of Teaching and Learning) at the University of Hong Kong. Recently, Nørgård (2021) also introduced the concept of hybridity, meaning that both physical and digital forms take place synchronously, for example through learning interactions that unfold as a coherent experience of being in multiple places at once.

\section{Related Studies}

\section{Engagement Within Hybrid Teaching and Learning Settings}

Although creating hybridity starts with technological solutions and set-ups, this is only one of the conditions creating the user experience within a certain setting, as no form of technology has the capacity to change practice (Stahl et al. 2014). In line with Goodyear et al. (2021), learning space is conceptualized as the ecosystem of learners, teachers, pedagogical practices, digital and material resources, buildings and furniture. This perspective aims to investigate the interrelations within this ecosystem. In that sense, it is crucial to investigate how people think about hybrid models of learning and teaching and to investigate how hybrid teaching and learning is experienced by both teachers and learners.

One of the main reasons why learning experience has been receiving much more attention over the last decade is that student engagement is regarded as one of the top factors affecting student performance (Furlong and Christenson 2008; Fredricks et al. 2004). Based on previous research and as shown in Fig. 2, we can state that engagement involves three dimensions: (1) behavioural (e.g. attending

Fig. 2 Three component model of engagement (Fredricks et al. 2004) 
lectures, asking question, participation in quizzes), (2) emotional (e.g. feelings of interest, sense of belonging, boredom, frustration or enjoyment) and (3) cognitive engagement (e.g. learning outcomes, metacognition and self-regulated learning). This three-component model has been used by several researchers in the past (e.g. Dobbins and Denton 2017; Gobert et al. 2015). In our research, we are particularly interested in unravelling emotional or affective engagement within the new learning spaces.

As literature stresses that student engagement is influenced by contextual variations such as learning environments (Bond and Bedenlier 2019; Fredericks et al. 2004; Raes et al. 2020; Shi et al. 2021) or teacher strategies (Heilporn et al. 2021), it is important to investigate how student engagement as an affective learning outcome is influenced both by the design of the synchronous hybrid learning environment as well as by the type of participation, given that students can access the hybrid classrooms in different ways (see Figs. 3, 4 and 5).

Previous research focusing on student engagement in hybrid classrooms is scarce (Raes et al. 2019; Lakhal et al. 2017; Miller et al. 2021), but the existing literature is consistent in that they all report that although hybrid education provides a lot of benefits, including flexibility, it brings many challenges, which are both pedagogical and technological in nature. The main pedagogical challenge reported in previous literature is that on-site students and remote students experience the lesson differently in the hybrid synchronous situation (Beatty 2007, 2019; Szeto 2014; Zydney et al. 2019), although the Research \& Development field strives for designing and implementing both pedagogical strategies and technological systems that enact comparable learning experiences (Butz et al. 2016; Butz and Stupnisky 2017; Cain et al. 2016). Previous research shows that remote learners feel a significant sense of distance towards their teacher and their faceto-face classmates (Ramsey et al. 2016). A qualitative study conducted by Olt (2018) concluded that the experience of the remote participant can be explained

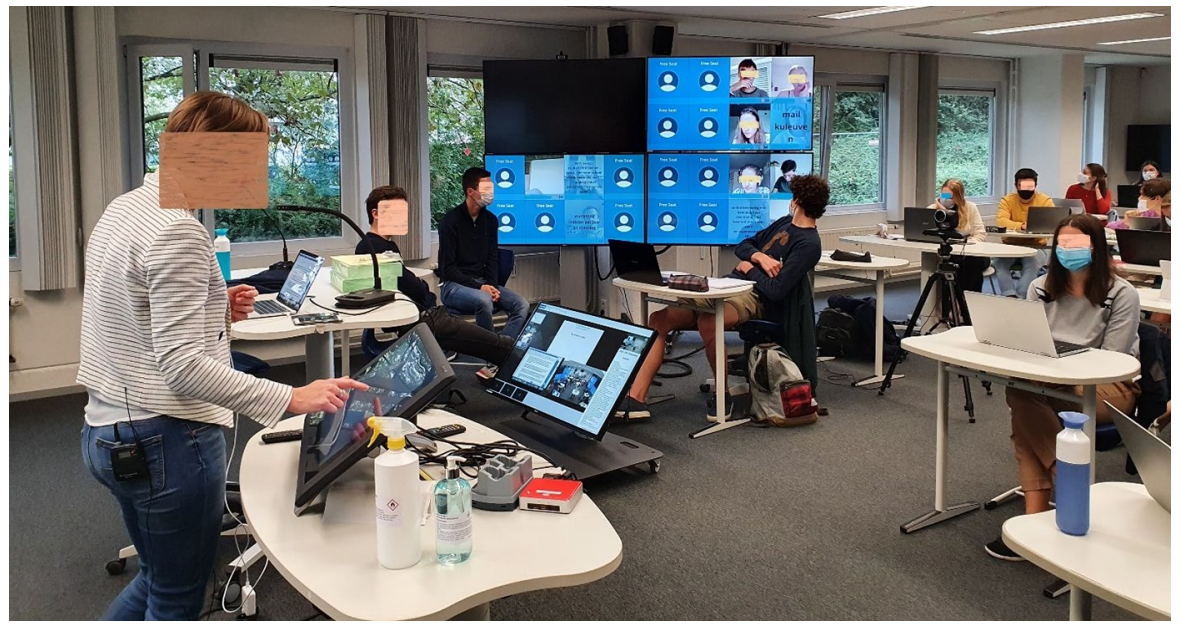

Fig. 3 Hybrid classroom@KU Leuven, Campus Kulak Kortrijk 


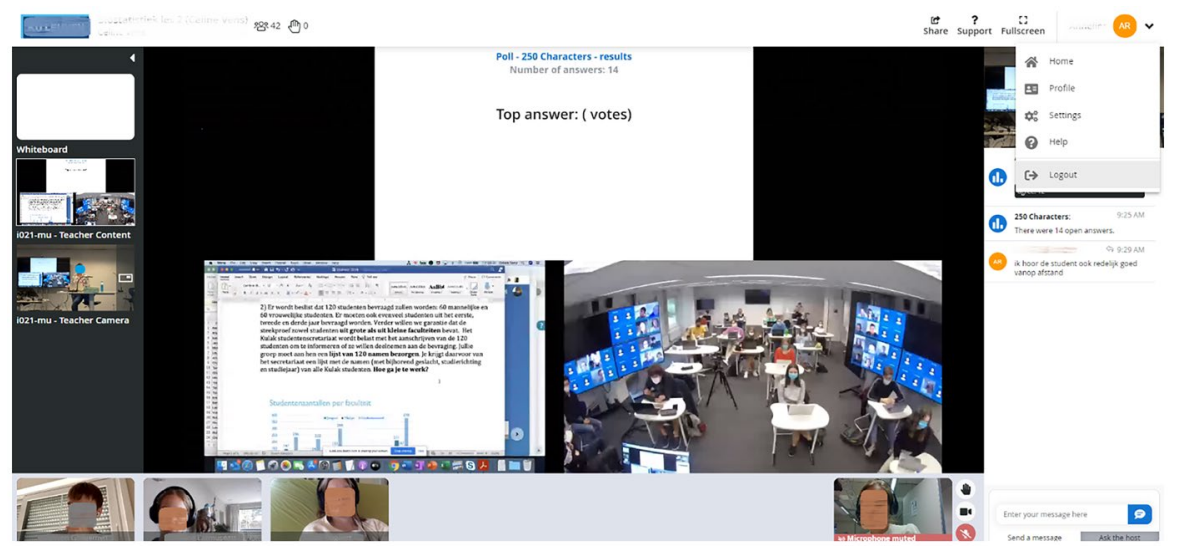

Fig. 4 Hybrid classroom from the perspective of the remote participant

and understood by the concept of 'ambiguity' in regard to group membership, functionality of technology, and place. Also, Huang et al. (2017) showed that the remote students felt excluded from the chief class, because they were physically separated from the face-to-face class, especially when the remote class encounters technical difficulties without immediate support. In the study of Weitze et al. (2013), remote students indicated that it is difficult to alert the teacher that they want to answer a question, which makes them feel frustrated and uninvolved. Therefore, it is important to take this into consideration in the design of the classes and to be aware that remote students need to feel more invited into the class activity.

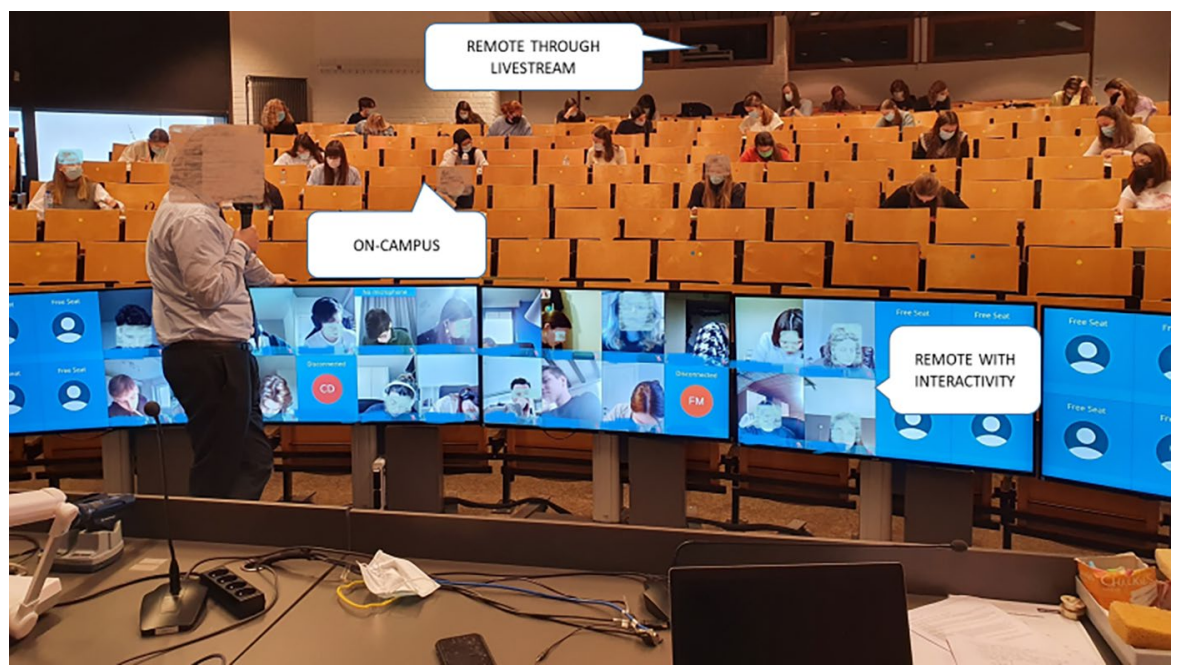

Fig. 5 Hybrid lecture hall@KU Leuven, Campus Kulak Kortrijk 


\section{Designing for Effective Teaching and Learning}

As stressed above, learning experience, and student engagement more particularly, is influenced by contextual variation. That same idea is shared by the founders of the activity-centred analysis and design (ACAD) framework (Carvalho and Goodyear 2014; Goodyear et al. 2021). Previous research has provided evidence on the fact that the way a learning environment is designed and which tools are provided matters for learning (Carvalho et al. 2020). The ACAD framework acknowledges the physical, epistemic and social situatedness of learning and conceptualizes this as set, epistemic and social design. Set design includes the specific tools, artefacts and learning space used to support learning and teaching. Epistemic design is related to the tasks or activities students are asked to do in service of learning, and social design is related to how students are grouped or how networks or communities are built. ACAD has previously been used to analyse emergent learning activity in both online and place-based spaces for networked learning. In this study, it will be used to describe the design of two synchronous hybrid learning practices and to analyse the results for student outcomes within these new settings.

Previous research within the context of hybrid education stresses that the loss of visual and audible cues, which normally are observable for the on-site students, impacts the learning and teaching experience (Weitze et al. 2013). In order to compensate for this loss and to mitigate for perceived distancing effects, it has been argued that teachers should frequently pause for questions throughout the lecture and be attentive to student responses (Heilporn et al. 2021; McGovern and Barnes 2009). In addition to this, students who attend the class remotely should perceive the same audio quality as students who are present face-to-face since the audio component has been found to be decisive for the success (Bower et al. 2015; Cunningham 2014). Irvine et al. (2013) found that synchronous hybrid tools that mimic face-toface delivery can help students maintain closer connections with peers. This means that next to audio quality, good video quality and an optimal framing of the teacher are challenges for the set design.

\section{Research Objective and Research Questions}

In this paper, I present the results of an exploration of learning and teaching experiences within synchronous hybrid environments. Although the concept of the synchronous hybrid learning spaces had been developed before the pandemic happened, this study describes the exploration of two types of design which have been tested during the Covid-19 pandemic. As displayed in Figs. 3 and 4, we differentiate between three levels of presence in the synchronous learning environment, i.e. (1) face-to-face or on campus, (2) remote, visible on the screen in the classroom and full interaction possible; (3) remote, following through livestream, not visible for the teacher and peers, not able to interact. 
From a student perspective, I aimed to answer the following research questions:

1. How does the level of presence (i.e. physical or remote presence) affect students' conceptual understanding?

2. How does the level of presence affect students' emotional or affective engagement during learning?

3. According to students, what are the determining factors to be engaged during synchronous hybrid lectures?

From a teacher perspective, this study aimed to investigate to following research question:

4. What are teachers' experiences during hybrid teaching and how does space affect their practice?

It has been claimed that it is important to investigate both the teacher perspective as well as the student perspective since what teachers do in their courses is linked with student engagement (Heilporn et al. 2021), but what teachers do or can do is also related to where they teach, i.e. the teaching space.

This study attempts to bridge this knowledge gap by presenting the student and teacher results of the exploration of two different postdigital learning spaces, where students engage with learning through different modes and with different levels of presence in the learning environment.

\section{Methodology}

\section{Research Design, Participants and Procedure}

This study is part of a larger university innovation, research and development project which is inspired on design-based research methodology in order to get a better theoretical understanding of effective teaching and learning in our new learning spaces and in order to be able to define evidence-based design-guidelines. The design-based research approach is frequently used in educational research conducted in authentic learning settings (McKenney and Reeves 2019). Designbased research (DBR) intends to produce new theories, artefacts and practices that account for and potentially impact learning and teaching in naturalistic settings (Barab and Squire 2004). It is characterized by its use of iterative cycles of design, enactment, analysis and redesign. As this paper presents teaching and learning in two different hybrid learning environments with differences in set-up and measured variables, this study needs to be viewed as a first exploration of these settings with the same research questions in mind.

In what follows, I focus firstly on the design in the two hybrid learning environments using the ACAD framework. This is followed by a description of the methodology. 


\section{Case Design Analysis 1: Problem-Based (Group) Learning in the Hybrid Classroom}

The first case is visualized in Figs. 3 and 4 displaying the hybrid classroom from the perspective of the on-site student and the remote student. Data has been collected within the course on Biostatistics attended by third-year bachelor students within the Faculty of Medicine at KU Leuven, Campus Kulak Kortrijk. Within this course, 45 third-year bachelor students participated in the study. The teacher is a female professor who has been teaching this course for 5 years. She is open to innovation and has been involved in teacher-researcher collaboration since 2017, within the context of the larger research project. The data collection within the course on Biostatistics was organized in September 2020. In the hybrid classroom, students can follow the course on-site and at the same time, remote students can connect synchronously. In this case, students were randomly divided over the two conditions (on-site versus remote presence).

Epistemic Design The learning activity organized in the hybrid classroom was built on the theory of delayed instruction or productive failure (Kapur 2016). The lecture started with a collaborative problem solving (CPS) task which was designed in line with the content of the lecture. Students were asked to set up a survey to evaluate the psychosocial wellbeing of students at campus. The focus of the task was not on how to formulate the questions of the survey, but rather on how to select the method of data collection, how to select a good sample, how to deal with randomness, how to deal with non-response, and how to solve the problem of over-and under-sampling through weights. In the second part of the lecture, the teacher taught the theory on sampling methods and bias in research including the input of the students.

Social Design Group learning was mainly integrated in the first part of the lecture. The remote students formed groups based on the screen on which they were displayed. On-site students formed groups based on their seating. In the second part of the lecture, the teacher interacted with both on-site and remote students by launching several polls.

Set Design The hybrid classroom facilitates launching quizzes and polls by using the Wacom tablet. By means of the same Wacom the teacher can start and end break-sessions. After launching a quiz or poll, the answers of the remote students become visible on the screens. Also, the names of the remote students are visible on the screens which means that the teacher can easily address to a certain remote student. As a remote participant, it is possible to choose between different sources (e.g. whiteboard, teacher camera, teacher content), and it is possible to ask questions in the chat. As a remote student, it is possible to raise your hand, to share your content, to mute or unmute yourself and to turn off your camera. Because of a ceiling microphone remote students can easily hear on-site students talking. 


\section{Case Design Analysis 2: Hybrid Lecture Hall}

The second case is visualized in Fig. 5 and consists of two lectures given within the same hybrid lecture hall, taught by two different professors within the Faculty of Law. Participants included 75 first-year bachelor students within the course on Contract law and 38 s-year bachelor students within the course on Family law. The Contract Law course is taught by a male professor and Family Law by a female professor. For both professors, it was the first time they participated in research within the context of the larger research project on learning spaces. Nevertheless both teachers were among the first users of the hybrid lecture hall. The data collection within the hybrid lecture hall was organized in March 2021.

Epistemic Design Both lectures could be described as theoretical sessions focusing on knowledge transmission. Both teachers asked oral questions during the lecture, without using polling software.

Social Design Students had been asked to subscribe in advance and they could indicate how they would follow the course, choosing between three options: on-site, remote on-screen with interactivity or remote through livestream. Places for option 1 and option 2 were restricted because of Covid-19 restrictions. No group work or break-out sessions were integrated in the sessions.

Set Design Up to 60 students can follow the course remotely by being displayed on the screen in front. Students could also choose to follow the course synchronously through livestream. Students who followed the session through livestream could not connect to the on-site students or the remote students visible on the screens. Remote students visible on the screens could easily answer the teacher's questions. Answers of remote students were audible through the boxes. As the hybrid lecture hall does not have a ceiling microphone, when on-site students answered to questions, this was not audible for remote students, unless the teacher passed on his/her microphone.

The three teachers who were responsible for the courses agreed to participate in the study to investigate student and teacher experiences during hybrid education. Their participation included data collection from their students and also required them to give an interview themselves. The research project 'Measuring and optimizing students' engagement in remote and (hybrid) virtual classrooms' has been evaluated and approved by the Social and Societal Ethics Committee of the university (G- 201806 1264). In line with our research protocol, students could voluntarily participate in the study by signing an informed consent. A week before the start of the course, students were informed about the objectives of the study by means of a 5-min video, which had been shared on the learning management platform. In addition to this video, informed consents have been collected in advance of the first survey. Participants were informed that they were going to be videotaped, that data from self-reports and from the learning platform was 
going to be collected, and that all data was going to be processed anonymously. Students were asked permission to be photographed during the courses.

\section{Data Collection and Measures}

As explained earlier, the set-up and data collection for both cases were slightly different, but within both cases the main objective was to investigate differences in student experiences regarding the level of presence (on-site versus remote) and to unravel the determining factor for student engagement. Below, the measured variables are described per case analysis. In both cases, a mixed-method approach has been used which implies the combination of quantitative and qualitative research methods (Cohen et al. 2011). This approach strengthens the inferences in the analysis of student experiences in this new learning space.

\section{Case Design Analysis 1}

To answer research questions 1 to 3 focusing on the student perspective, quantitative data has been collected through a pre- and post-test. The pre-test aimed to measure prior knowledge on sampling methods and bias. The post-test aimed to measure the gain in conceptual knowledge and measured students' intrinsic motivation, experienced relatedness and perceived value of past learning activities by means of validated scales based on the self-determination theory (Deci and Ryan 1985). At the end of the post-test, students could add open thoughts about the course and they were asked for suggestions for improvement.

\section{Case Design Analysis 2}

In terms of the courses given at the Faculty of Law, we were only able to conduct a post-intervention survey measuring student engagement, yet in this setting, we explored different scales to get a better sense of the emotional engagement in this new learning space. Next to the scales borrowed from the self-determination theory (Deci and Ryan 1985), case study 2 included the Eduflow scales Flow and Cognitive Absorption (Heutte et al. 2016) and a measurement of Sense of Presence (Barfield and Weghorst 1993; Dinh et al. 1999) and Sense of Belonging (Yorke 2016). The list of variables is presented in Table 1, providing sample items for the different variables and the accompanying reliability scores. The Cronbach's alphas regarding the different subscales indicate that the scales were reliable. At the end of the course, students could complete the digital survey supported by Qualtrics software in about 15 min by means of their smartphone or their personal computer. Qualitative data consisted of open answers given by the students at the end of the questionnaire, where they were asked about the determining factors for student engagement and about whether they had any open suggestions for improvement.

To answer research question 4 focusing on the teacher perspective, a semi-structured interview has been organized with each teacher separately in order to get insight into their experiences and thoughts about hybrid teaching and learning. 


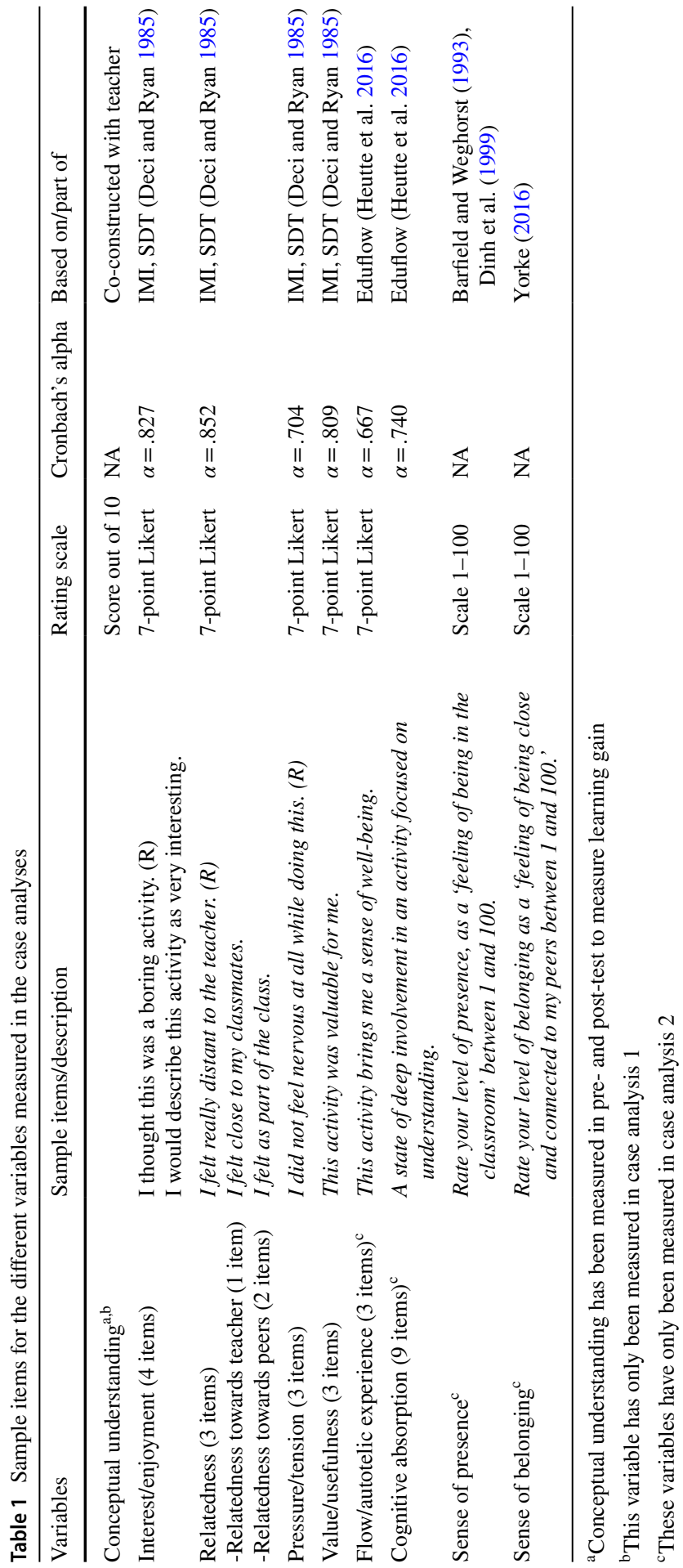




\section{Data Analysis}

Quantitative data has been analysed by means of the statistical software package SPSS. As we were particularly interested in possible differences between conditions, independent $t$-tests and ANOVAs have been conducted regarding the different dependent variables (see Table 1), including learning setting as a fixed factor. One sample $t$-test has been used to investigate if scores significantly differed from the neutral score. Regarding case study 1, where next to affective engagement also cognitive understanding has been measured, an analysis of covariance has been carried out to investigate the effect of the learning setting on learning gain.

Qualitative data including both written answers from students and teachers' transcribed interviews have first been analysed inductively. Content analysis was used to generate common experiences and valuable feedback regarding their experience of learning and teaching in the hybrid classroom and to give a deeper insight into the quantitative data. Subsequently, students' answers about the determinants for engagement have been clustered based on the ACAD framework, allowing us to better analyse the connections between design elements and students' engagement.

\section{Results}

\section{How Does the Level of Presence Affect Students' Conceptual Understanding?}

The first research question could only be tested in the first experiment, which included the third-year bachelor students who had participated in the pre-test-post-test design. With regard to students' conceptual understanding, an analysis of covariance revealed no differences between both conditions. This means that all students achieved significant learning gains and that remote and on-site students scored equally on the posttest (after controlling for pre-test scores) (see Table 2).

Table 2 Conceptual understanding between remote and on-site students (Case analysis 1)

\begin{tabular}{|c|c|c|c|c|}
\hline \multirow{3}{*}{$\begin{array}{l}\text { Dependent variable: } \\
\text { conceptual understand- } \\
\text { ing }\end{array}$} & \multicolumn{4}{|c|}{ Level of presence as independent variable } \\
\hline & $\begin{array}{l}\text { Remote students } \\
\text { present from a } \\
\text { distance }\end{array}$ & $\begin{array}{l}\text { On-site students } \\
\text { physically } \\
\text { present }\end{array}$ & Statistical testing & Significance \\
\hline & $M(S D)$ & $M(S D)$ & $\begin{array}{l}\text { Independent sample } \\
\text { t-test }\end{array}$ & p-value \\
\hline Pre-test score out of 10 & $3.53(2.66)$ & $3.98(2.51)$ & .54 & .59 \\
\hline $\begin{array}{l}\text { Post-test score out } \\
\text { of } 10\end{array}$ & $6.48(1.50)$ & $6.66(1.88)$ & .34 & .73 \\
\hline
\end{tabular}




\section{How Does the Level of Presence Affect Students' Engagement during Learning?}

Regarding students' affective engagement, significant differences were found when comparing the different learning settings in both experiments. Table 3 presents the results revealed in case analysis 2 comparing three different levels of presence.

On-campus students showed to experience high levels of affective engagement operationalized as 1. enjoyment, 2. relatedness, 3. pressure, 4. value, 5. autotelic experience, 6. cognitive absorption, 7. sense of belonging and 8. sense of presence. Regarding on-site students $(N=58)$, all means significantly differ from the neutral score. As for remote students, significant differences were found between visible and invisible remote students with significant higher engagement scores for students who were visible on the screens compared to students following the course through livestream.

Based on these findings and based on additional qualitative comments, we can state that the feature of the remote setting, i.e. being displayed in the classroom and being able to interact with the teacher, influences students' engagement.

It's easy to follow the lesson and it's good to see other students as well.

Because you turn on the camera and interact, you are obliged to be more attentive than you would be when following any other type of class remotely.

(remote student, case analysis 1)

The results for sense of presence and sense of belonging show that it is easier to realize a sense of presence, conceived as a feeling of being in the classroom, than to create a sense of belonging, conceived as a feeling of being close and connected to your peers. It is important to note that during case analysis 2 no group work or breakout sessions were organized, whereas this was the case in case analysis 1.

Table 3 Comparison of affective engagement scales in the different learning settings

\begin{tabular}{|c|c|c|c|c|}
\hline \multirow[t]{3}{*}{ Dependent variables } & \multicolumn{4}{|c|}{ Educational setting as independent variable } \\
\hline & $\frac{\text { On campus }}{(\mathrm{N}=58)}$ & $\begin{array}{l}\text { Remote on screen } \\
\text { with interaction (N } \\
=33)\end{array}$ & $\begin{array}{l}\text { Remote through } \\
\text { livestream }(\mathrm{M} \\
=15)\end{array}$ & $\begin{array}{l}\text { Significance } \\
\text { of ANOVA's }\end{array}$ \\
\hline & $M(S D)$ & $M(S D)$ & $M(S D)$ & \\
\hline 1. Interest/enjoyment (1-7) & $5.67(0.78)^{*}$ & $4.57(1.01)^{*}$ & $3.83(1.41)$ & $<.001$ \\
\hline 2. Relatedness $(1-7)$ & $5.05(1.20) *$ & $4.02(0.98)$ & $3.13(1.51)$ & $<.001$ \\
\hline 3. Pressure/tension (1-7) & $3.05(1.11) *$ & $3.46(1.13)^{*}$ & $3.84(1.37)$ & $<.05$ \\
\hline 4. Value/usefulness (1-7) & $5.60(0.76)^{*}$ & $5.36(0.78)^{*}$ & $4.76(1.01)^{*}$ & $<.01$ \\
\hline $\begin{array}{l}\text { 5. Flow/autotelic experience } \\
(1-7)\end{array}$ & $4.46(1.14) *$ & $4.01(1.09)$ & $3.57(0.94)$ & $<.01$ \\
\hline 6. Cognitive absorption (1-7) & $4.46(0.90) *$ & $4.44(0.78)^{*}$ & $3.75(0.84)$ & $<.05$ \\
\hline 7. Sense of presence $(1-100)$ & $90(13) *$ & $74(14)^{*}$ & $51(26)$ & $<.001$ \\
\hline 8. Sense of belonging $(1-100)$ & $84(21)^{*}$ & $49(26)$ & $32(26)^{*}$ & $<.001$ \\
\hline
\end{tabular}

Mean scores presented in bold with an asterisk do significantly differ from the neutral score (i.e. 4 for variables 1 to 6 measured on a 7-point Likert scale, and 50 for variables 7 and 8 measured on a scale 1-100) 
Qualitative data from this first analysis reveals that group work (as part of social design) might have influenced the sense of belonging.

I found it useful to work together in small groups online. You feel less alone and there is a good interaction with the professor. (remote student visible on screen with interaction, case analysis 1)

Moreover, qualitative feedback indicates that remote students were surprised that being at a physical distance did not preclude affective presence and connectivity:

Even though I was not physically present, I felt connected to the fellow students. (remote student visible on screen with interaction, case analysis 1)

Unfortunately, during case analysis 1 , we did not collect scores for sense of presence and sense of belonging.

\section{According to Students, What are the Determining Factors for Engagement during Synchronous Hybrid Lectures?}

By means of an open question, all participants of case analysis 2 were asked to answer the following question: 'What is, according to you, the most determining factor for engagement during the synchronous course?'. Ninety-six students answered this question and all answers were analysed and categorized based on the ACAD framework (Goodyear et al. 2021). Task or student activity-related answers were categorized under Epistemic Design. Answers related to the learning space, the set-up, and the features of the space, were categorized under Set Design. Finally, answers referring to peers and the community of learners were categorized under Social Design.

As displayed in Fig. 6, 34 out of 96 (35\%) students referred to the epistemic design as the most determining factor for engagement during a course, 31 (33\%)

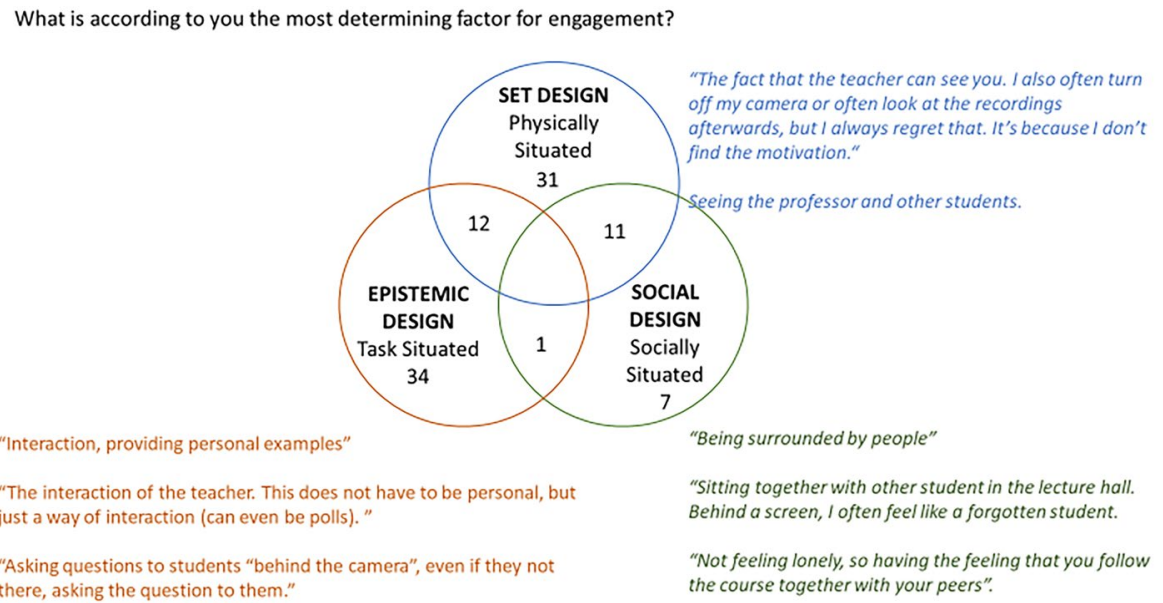

Fig. 6 Students' answers categorized based on the ACAD framework (Goodyear et al. 2021) 
referred to the set design, and 7 referred to social design. Some of the answers could be categorized under two categories. The following citation for example is both linked to set and social design:

Personally, what is determining for me, is feeling the 'atmosphere' in the auditorium, at home you cannot hear the conversation that is going on between your peers that are physically present at campus, that makes me feel excluded as a remote student. (remote student visible on screen with interaction, case analysis 2)

A combination of set and epistemic design has been found as well, in the following statement:

What is determining for me, is being present in the room and experiencing a real-life lecture and being able to interact with the teacher who can ask you a question anytime. (remote student through livestream, case analysis 2)

\section{How Does the Teaching Space Affect Teaching Practice?}

Next to investigating students' engagement in hybrid settings, additionally, this study sought to gain insight into the way in which teachers experience hybrid teaching and how space affects their practice. The results are given based on three 1-hour interviews with the professors who taught in the new learning context. These teachers have not only been teaching in the hybrid classroom and hybrid lecture hall shown respectively in Figs. 3, 4 and 5, but also used other solutions during the past year. At some times, strict lockdown requirements prevented students and teachers from coming to the campus altogether. During these times, teachers used systems like Blackboard (BB) Collaborate or Teams, both of which are provided at the institution and could be used from any place. Given the fact that these teachers have taught in many settings, they could easily come up with an answer to the question of what affects their teaching practice. Each interview started with an overview of the (anonymized) results collected in cooperation with their students. Next, it was stated that in the remaining time, we would focus on the teaching space instead of the learning space.

When comparing their teaching experience in the hybrid classroom/lecture hall with their experience using alternative systems (i.e. Teams and/or BB Collaborate), designed to teach from home, actually seeing the students was mentioned as the main advantage of the design of the hybrid classroom and hybrid lecture hall. Teachers mentioned that, in the alternative systems, students can see the presenting teacher in combination with the slides, but the teacher is not always able to see the students, or only a small number of them. Most of the time, they argue, students turn off their camera and their microphone. Teachers reveal that although it was indicated that students could ask questions using the chat, interaction was nearly non-existent.

One of the teachers described teaching from home and sitting behind the screen as cold and detached. That teacher also taught several classes just before the Christmas period in an empty auditorium, to which students were connected through livestream. That teacher mentioned that she had shared her feeling of loneliness with the students and once brought Christmas lights to decorate her desk to improve the astrosphere. 
According to that teacher, this small change to the teaching space really made a difference both for the students and the teacher. She also added that she even prefers livestream teaching over teaching behind a desk, as during livestream recording within an auditorium, students can at least see the posture of the teacher within the teaching environment and not only their face. In line with this, another teacher mentioned that (s)he likes to use a lot of gestures during teaching which do not come across as well when teaching behind a screen.

All the teachers revealed that teaching feels much more natural and intuitive in the hybrid classroom/hybrid lecture hall, because they have space to walk around, they are able to write something on a whiteboard, and, most importantly, they can interact with their students because they are visible on the screens. The teachers mentioned that they often tend to interact with their students based on their facial expressions: 'You can see it on their faces if they do not understand something'. One of the teachers pointed out that when teaching a course without seeing your students, it is very difficult to evaluate the quality of your course. The teacher stated the following: "you are only able to evaluate your own performance, but it is so much nicer to get something in return and to feel and see to what extent your message has arrived and been understood by your students'.

When asking the teachers what would be their ideal scenario for a future without restrictions, the three teachers were all looking forward to teaching again in the auditorium with all students present. One of the teachers revealed that (s)he missed the crowded auditoria, sometimes so full that students even had to sit on the stairs. 'This gives you the kick and the adrenaline you need to give a good performance; whether you are a speaker, athlete, teacher, or actor, having an audience is very important to perform'.

In all three of the interviews, the value and limitations of recording sessions was briefly discussed. A shared observation at our university, but also at universities worldwide, is that synchronous learning activities are attracting less and less students as students seem to prefer to watch lesson recordings. All teachers revealed that they agree that in some case recordings can be useful, for example for students who cannot attend the course if they combine work and study. Still, watching asynchronous recordings should not be seen as an equal alternative for attending the synchronous course.

\section{Discussion and Conclusion}

Looking into the literature on hybrid learning environments, it is generally viewed as both engaging and relevant due to its high level of flexibility (Nørgård 2021). More and more researchers claim that the nature and structure of future universities will be hybrid to better deal with changing contexts (Miller et al. 2021). This will entail that physical and digital learning and research environments must be designed in a holistic way in order to accommodate the different needs of a diverse university community. Hybrid learning environments allowing learners to attend synchronous online courses at home, at work or when traveling, are not new in the field. The last 15 years, new educational models have been proposed such as HyFlex learning and 
teaching conceptualized by Beatty $(2007,2019)$ and multi-access education conceptualized by Irvine et al. (2013). Yet to be able to make thoughtful design decisions, more empirical research is needed about how these new learning spaces are experienced by both students and teachers, as the latter has often been neglected in previous research. Moreover, research is needed to inform pedagogy in these postdigital learning spaces. This paper aimed to fill this knowledge gap by both studying the learning and the teaching space through the lens of the ACAD framework. Since one of the key components for optimal experience is engagement, this study first investigated this multidimensional construct by quantitatively using different theoretical constructs. Second, by means of a qualitative approach, this study shed light on the determining factors to foster engagement during hybrid teaching and learning.

This research revolved around four research questions, three of them focusing on the student perspective, one of them focusing on the teacher perspective. Regarding the student perspective, this study did not find any significant differences between the levels of presence (i.e. physical and remote presence) in terms of conceptual understanding, yet significant differences were found regarding affective engagement, including intrinsic motivation, relatedness, experienced pressure, cognitive absorption, autotelic experience, sense of presence and sense of belonging. These findings are in line with previous research claiming that on-site students and remote students experience courses differently in the hybrid synchronous situation (Beatty 2007, 2019; Szeto 2014; Zydney et al. 2019). Nevertheless, this study provided both quantitative and qualitative evidence that the design of the learning space really does matter to the remote experience. Students following the course through livestream without interaction or visibility to the teachers had the lowest engagement scores. Next, the qualitative data in relation to research question 3 showed that one out of three students referred to the set design as being determinant for being engaged during synchronous courses. This is in line with what previously has been claimed by Irvine et al. (2013), namely that synchronous hybrid tools that mimic face-to-face delivery can help students maintain closer connections. Yet, it is also known that having the innovative infrastructure will not guarantee anything. In line with the ACAD framework, successful learning is interrelated with set, epistemic and social design decisions, and this was also reflected in the results of this study. Two-thirds of the students indicated that the actions of the teacher during the course (epistemic design) and having the feeling that you are not alone (social design) are the most important for engendering engagement. Nonetheless, social design and epistemic design are closely interrelated with set design, as a certain teaching space can better support interaction and sense of belonging. Regarding our fourth research question, it has been explored how teachers experienced the teaching space, as those experiences have drastically changed over the course of the past year. The teachers expressed that they felt lucky to have experienced the new teaching spaces as they believe that the spaces supported them in qualitative teaching, and they believe that the facilities of the new spaces serve to engage both staff and students (Joy et al. 2013). Yet, we should be realistic in the sense that not every space will have all the facilities included. Next, when having huge student groups, the livestream option will still be used in future education. In these settings it will be important to incorporate live engagement, e.g. through polls and/or quizzes. Previous research has 
shown that using quizzes is effective for increasing engagement (Raes et al. 2020). This means that to design supportive hybrid learning and teaching it is crucial to take into consideration pedagogical, social and technical elements as being part of the epistemic, social and set design of a learning and teaching space.

\section{Limitations and Suggestions for Future Research}

Several limitations should be noted in this study. First of all, the case design analyses should be seen as explorations within the new settings and not as experiments which are comparable and generalizable. The differences between the cases do not allow the study to make generalizations to other postdigital learning spaces. Second, the present study only investigated academic performance in the first case analysis. It will be important to include academic performance in future research studies to investigate if our finding can be replicated. Although just a first step in investigating teaching and learning experiences in new synchronous hybrid learning settings, this paper highlights the importance of both the level of presence and the design of the space to support effective learning and teaching in hybrid learning spaces.

Acknowledgements I would like to thank the professors and students from KU Leuven, campus Kulak Kortrijk for their participation and their thoughtful feedback regarding this research.

Funding This study was carried out within imec's Smart Education research programme, with support from the Flemish government and funding from KU Leuven University. This project was also supported by the French government through the Programme Investissement d'Avenir (I-SITE ULNE / ANR-16IDEX-0004 ULNE) managed by the Agence Nationale de la Recherche.

\section{Declarations}

Ethical Approval and Informed Consent This research involves human participants, but this research project has been reviewed and approved by the Social and Societal Ethics Committee https://ppw.kuleuven. be/home/onderzoek/SMEC). Informed consent was obtained from all individual participants included in the study.

Conflict of Interest The author declares no competing interests.

\section{References}

Amoroso, C. (2014). Hybrid by Choice. Increasing Engagement in a High Enrollment Course. Hybrid Pedagogy, 20 May. https://hybridpedagogy.org/hybrid-choice-increasing-engagement-high-enrollment-course/. Accessed 14 November 2021.

Barab, S., \& Squire, K. (2004). Design-based research: Putting a stake in the ground. Journal of the Learning Sciences, 13(1), 1-14. https://doi.org/10.1207/s15327809j1s1301_1.

Barfield, W., \& Weghorst, S. (1993). The sense of presence within virtual environments: A conceptual framework. In G. Salvendy \& M. Smith (Eds). Human-computer interaction: Applications and case studies (pp. 699-704). Amsterdam: Elsevier. 
Beatty, B. J. (2007). Hybrid classes with flexible participation options - If you build it, how will they come? Paper presented at the 2007 Association for Educational Communications and Technology Annual Convention (October). Anaheim, CA: Association for Educational Communications and Technology. http://citeseerx.ist.psu.edu/viewdoc/download?doi=10.1.1.457.495\&rep=rep1\&type= pdf. Accessed 14 November 2021.

Beatty, B. J. (2019). Hybrid-Flexible Course Design: Implementing student-directed hybrid classes. EdTech Books.

Bell, J., Sawaya, S., \& Cain, W. (2014). Synchromodal classes: Designing for shared learning experiences between face-to- face and online students. International Journal of Designs for Learning, 5(1). https://doi.org/10.14434/ijdl.v5i1.12657.

Bond, M., \& Bedenlier, S. (2019). Facilitating student engagement through educational technology: Towards a conceptual framework. Journal of Interactive Media in Education, 1, 1-14. https://doi. org/10.5334/jime.528.

Bower, M., Dalgarno, B., Kennedy, G. E., Lee, M. J. W., \& Kenney, J. (2015). Design and implementation factors in blended synchronous learning environments: Outcomes from a cross-case analysis. Computers \& Education, 86, 1-17. https://doi.org/10.1016/j.compedu.2015.03.006.

Butz, N. T., \& Stupnisky, R. H. (2017). Improving student relatedness through an online discussion intervention: The application of self-determination theory in synchronous hybrid programs. Computers and Education, 114, 117-138. https://doi.org/10.1016/j.compedu.2017.06.006.

Butz, N. T., Stupnisky, R. H., Pekrun, R., Jensen, J. L., \& Harsell, D. M. (2016). The Impact of Emotions on Student Achievement in Synchronous Hybrid Business and Public Administration Programs: A Longitudinal Test of Control-Value Theory*. Decision Sciences Journal of Innovative Education, 14(4), 441-474. https://doi.org/10.1111/dsji.12110.

Cain, W., Bell, J., \& Cheng, C. (2016). Implementing robotic telepresence in a synchronous hybrid course. In Proceedings of IEEE 16th International Conference on Advanced Learning Technologies, ICALT 2016. (pp. 171-175). New York: The Institute of Electrical and Electronics Engineers, Inc. https://doi.org/10.1109/ICALT.2016.79.

Carvalho, L., \& Goodyear, P. (2014). The architecture of productive learning networks. New York: Routledge.

Carvalho, L., Nicholson, T., Yeoman, P., \& Thibaut, P. (2020). Space matters: framing the New Zealand learning landscape. Learning Environments Research, 23(3), 307-329. https://doi.org/10.1007/ s10984-020-09311-4.

Cohen, L., Manion, L., \& Morrison, K. (2011). Research Methods in Education. 7th Ed. London: Routledge.

Cunningham, U. (2014). Teaching the Disembodied: Othering and Activity Systems in a Blended Synchronous Learning Situation. International Review of Research in Open and Distance Learning, 15(6). https://doi.org/10.19173/irrodl.v15i6.1793.

Deci, E. L., \& Ryan, R. M. (1985). The general causality orientations scale - self-determination in personality. Journal of Research in Personality, 19(2), 109-134. https://doi.org/10.1016/0092-6566(85) 90023-6.

Dinh, H. Q., Walker, N., Song, C., Kobayashi, A., \& Hodges L.F. (1999). Evaluating the importance of multi-sensory input on memory and the sense of presence in virtual environments. In L. Rosenblum, P. Astheimer, \& D. Teichmann (Eds.), Proceedings of the IEEE Virtual Reality 1999 (pp. 222-228). Los Alamitos, CA: The Institute of Electrical and Electronics Engineers, Inc. https://doi.org/10.1109/VR. 1999.756955.

Dobbins, C., \& Denton, P. (2017). MyWallMate: An Investigation into the use of Mobile Technology in Enhancing Student Engagement. TechTrends, 61(6), 541-549. https://doi.org/10.1007/ s11528-017-0188-y.

European University Association. (2021). Universities without walls. A vision for 2030. Brussels: European University Association. https:/eua.eu/downloads/publications/universities without walls a vision for 2030.pdf. Accessed 14 November 2021.

Feenberg, A. (2019). Postdigital or Predigital? Postdigital Science and Education, 1(1), 8-9. https://doi. org/10.1007/s42438-018-0027-2.

Fredricks, J. A., Blumenfeld, P. C., \& Paris, A. H. (2004). School Engagement: Potential of the Concept, State of the Evidence. Review of Educational Research, 74(1), 59-109. https://doi.org/10.3102/ 00346543074001059 . 
Furlong, M. J., \& Christenson, S. L. (2008). Engaging students at school and with learning: A relevant construct for all students. Psychology in the Schools, 45(5), 365-368. https://doi.org/10.1002/pits. 20302.

Gobert, J. D., Baker, R. S., \& Wixon, M. B. (2015). Operationalizing and Detecting Disengagement Within Online Science Microworlds. Educational Psychologist, 50(1), 43-57. https://doi.org/10. 1017/CBO9781107415324.004.

Goodyear, P., Carvalho, L., \& Yeoman, P. (2021). Activity-Centred Analysis and Design (ACAD): Core purposes, distinctive qualities and current developments. Educational Technology Research and Development, 0123456789. https://doi.org/10.1007/s11423-020-09926-7.

Heilporn, G., Lakhal, S., \& Bélisle, M. (2021). An examination of teachers' strategies to foster student engagement in blended learning in higher education. International Journal of Educational Technology in Higher Education, 18(1). https://doi.org/10.1186/s41239-021-00260-3.

Heutte, J., Fenouillet, F., Martin-Krumm, C., Boniwell, I., \& Csikszentmihalyi, M. (2016). Proposal for a conceptual evolution of the flow in education (EduFlow) model. Presented at 8th European Conference on Positive Psychology (ECPP2016), Angers, France. https://hal.archives-ouvertes.fr/hal01470857. Accessed 14 November 2021.

Huang, Y., Shu, F., Zhao, C., \& Huang, J. (2017). Investigating and analyzing teaching effect of blended synchronous classroom. In Proceedings of 6th International Conference of Educational Innovation Through Technology (EITT) (pp. 134-135). New York: The Institute of Electrical and Electronics Engineers, Inc. https://doi.org/10.1109/EITT.2017.40.

Irvine, V. (2020). The Landscape of Merging Modalities. Educause Review, 4, 40-58. https://er.educause. edu/articles/2020/10/the-landscape-of-merging-modalities. Accessed 9 May 2021.

Irvine, V., Code, J., \& Richards, L. (2013). Realigning Higher Education for the 21st-Century Learner through Multi-Access Learning. Journal of Online Learning and Teaching, 9(2).

JISC. (2006). Designing Spaces for Effective Learning A guide to 21st century learning space design. http://www.online-conference.net/jisc/content/designspaces.pdf. Accessed 14 November 2021.

Joy, M., Foss, J., King, E., Sinclair, J., Sitthiworachart, J., \& Davis, R. (2013). Incorporating technologies into a flexible teaching space. British Journal of Educational Technology, 45(2), 272-284. https://doi.org/10. 1111/bjet.12040.

Kapur, M. (2016). Examining Productive Failure, Productive Success, Unproductive Failure, and Unproductive Success in Learning. Educational Psychologist, 51(2), 289-299. https://doi.org/10.1080/ 00461520.2016 .1155457$.

Ladd, T. (2020). Optimizing concurrent classrooms: Teaching students in the room and online simultaneously. Forbes, 19 June. https://www.forbes.com/sites/tedladd/2020/06/19/optimizing-concurrentclassrooms-teaching-students-in-the-room-and-online-simultaneously/\#50645ba93451. Accessed 14 November 2021.

Lakhal, S., Bateman, D., \& Bédard, J. (2017). Blended Synchronous Delivery Mode in Graduate Programs: A Literature Review and Its Implementation in the Master Teacher Program. Collected Essays on Learning and Teaching, 10. http://dx.doi.org/10.22329/celt.v10i0.4747.

Miller, A. N., Sellnow, D. D., \& Strawser, M. G. (2021). Pandemic pedagogy challenges and opportunities: instruction communication in remote, HyFlex, and BlendFlex courses. Communication Education, 70(2), 202-204. https://doi.org/10.1080/03634523.2020.1857418.

McGovern, N., \& Barnes, K. (2009). Lectures from My Living Room: A Pilot Study of Hybrid Learning from the Students' Perspective. In F. L. Wang, J. Fong, L. Zhang, \& V. S. K. Lee (Eds.), Hybrid Learning and Education (pp. 284-298). Berlin, Heidelberg: Springer. https://doi.org/10.1007/9783-642-03697-2_27.

McKenney, S., \& Reeves, T. C. (2019). Conducting Educational Design Research. New York: Routledge.

Nørgård, R. T. (2021). Theorising hybrid lifelong learning. British Journal of Educational Technology. https://doi.org/10.1111/bjet.13121.

O’Byrne, W. I., \& Pytash, K. E. (2015). Hybrid and Blended Learning: Modifying Pedagogy Across Path, Pace, Time, and Place. Journal of Adolescent and Adult Literacy, 59(2), 137-140. https://doi.org/10. 1002/jaal.463.

Olt, P. A. (2018). Virtually There: Distant Freshmen Blended in Classes through Synchronous Online Education. Innovative Higher Education, 43(5), 381-395. https://doi.org/10.1007/ s10755-018-9437-z. 
Raes, A., Detienne, L., Windey, I., \& Depaepe, F. (2019). A systematic literature review on synchronous hybrid learning: gaps identified. Learning Environments Research, 23(3), 269-290. https://doi.org/ 10.1007/S10984-019-09303-Z.

Raes, A., Vanneste, P., Pieters, M., Windey, I., Van Den Noortgate, W., \& Depaepe, F. (2020). Learning and instruction in the hybrid virtual classroom: An investigation of students' engagement and the effect of quizzes. Computers and Education, 143. https://doi.org/10.1016/j.compedu.2019.103682.

Ramsey, D., Evans, J., \& Levy, M. (2016). Preserving the seminar experience. Journal of Political Science Education, 12(3), 256-267. https://doi.org/10.1080/15512169.2015.1077713.

Shi, Y., Tong, M., \& Long, T. (2021). Investigating relationships among blended synchronous learning environments, students' motivation, and cognitive engagement: A mixed methods study. Computers and Education, 168. https://doi.org/10.1016/j.compedu.2021.104193.

Stahl, G., Koschmann, T., \& Suthers, D. (2014). Computer-supported collaborative learning: An historical perspective. In R. K. Sawyer (Ed.), Cambridge handbook of the learning sciences, revised version (pp. 479-500). Cambridge, UK: Cambridge University Press.

Szeto, E. (2014). A Comparison of Online/Face-to-face Students' and Instructor's Experiences: Examining Blended Synchronous Learning Effects. Procedia - Social and Behavioral Sciences, 116, 42504254. https://doi.org/10.1016/j.sbspro.2014.01.926.

Wang, Q., Huang, C., \& Quek, C. L. (2018). Students' perspectives on the design and implementation of a blended synchronous learning environment. Australasian Journal of Educational Technology, 34(1), 1-13. https://doi.org/10.14742/ajet.3404.

Weitze, C. L., Ørngreen, R., \& Levinsen, K. (2013). The Global Classroom Video Conferencing Model and First Evaluations. I M. Ciussi \& M. Augier (Eds.), Proceedings of the 12th European Conference on E-Learning: SKEMA Business School, Sophia Antipolis France, 30-31 October 2013 (pp. 503-510). Reading, UK: Academic Conferences and Publishing International.

Yorke, M. (2016). The development and initial use of a survey of student 'belongingness,' engagement and self-confidence in UK higher education. Assessment \& Evaluation in Higher Education, 41(1), 154-166. https://doi.org/10.1080/02602938.2014.990415.

Zydney, J. M., McKimm, P., Lindberg, R., \& Schmidt, M. (2019). Here or There Instruction: Lessons Learned in Implementing Innovative Approaches to Blended Synchronous Learning. TECHTRENDS, 63(2), 123-132. https://doi.org/10.1007/s11528-018-0344-z.

Zydney, J. M., Warner, Z., \& Angelone, L. (2020). Learning through experience: Using design based research to redesign protocols for blended synchronous learning environments. Computers and Education, 143. https://doi.org/10.1016/j.compedu.2019.103678.

Publisher's Note Springer Nature remains neutral with regard to jurisdictional claims in published maps and institutional affiliations. 